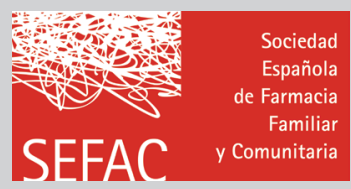

\title{
¿Qué es la "Alianza contra el asma"?
}

\section{Javier Plaza Zamora}

Vocal de la Junta Directiva y coordinador de los Grupos de Trabajo de SEFAC.

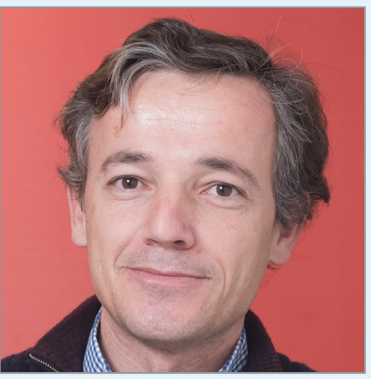

Javier Plaza Zamora

PALABRAS CLAVE

Asma, agonistas- $\beta 2$,

farmacia comunitaria

\section{KEYWORDS}

Asthma, $\beta 2$-agonists, community pharmacy
Nuria, paciente de la farmacia desde hace años, viene alteradísima en busca de salbutamol 100 microgramos en inhalación para su marido Paco, que lo tiene en la receta electrónica. Acaban de echar a su marido de la empresa y según comenta Nuria "está para que le dé algo". Tras revisar la dispensación de salbutamol de los últimos meses observo que, con el que me ha pedido, es el segundo envase en el último mes. Parece un poco excesivo, así que le pregunto por cómo lleva el asma su marido y me responde que aparentemente bien, en cuanto se encuentra mal usa el inhalador y vuelve a lo que está haciendo... A continuación, me dice que el jefe de Paco le ha echado a la calle porque no rinde en su faena; el cansancio le está haciendo mella en su quehacer diario. ¿Puede que no tenga controlada su asma? ¿Es posible que no esté usando su tratamiento de mantenimiento? ¿Podría Paco realizar sus tareas como una persona que no fuera asmática?

En España entorno al 5\% de los adultos y al 10\% de los niños son asmáticos. El control de los sintomas de la enfermedad, según el estudio Realise (1), realizado en diferentes países de la Unión Europea, incluyendo el nuestro, no fue bueno en más de un 50\% de los 8.000 pacientes asmáticos adultos encuestados. ¿Cuántos pacientes asmáticos podrían tener del todo controlada su enfermedad?, pues según el estudio Magic (2), de los 1.363 pacientes analizados en España, solamente un 13,6\% tenía perfectamente controlada su sintomatología.

Cuando el paciente asmático tiene una crisis, suele recurrir a su inhalador de rescate ( $\beta-2$ adrenérgico de acción corta) para paliar la disnea presente y cuando la necesidad de esa medicación de rescate es mayor a dos veces por semana se considera que su asma está parcialmente controlada, por lo que debería revisarse su plan de tratamiento y analizar las causas de este descontrol hasta conseguir un buen control de su patología (3).
En este contexto nace Alianza contra el asma, programa orientado a mejorar la salud del paciente asmático, en la cual participa la Sociedad de Respiratorio de Atención Primaria (GRAP), la Sociedad Española de Farmacia Familiar y Comunitaria (SEFAC) y la Federación Española de Asociaciones de pacientes alérgicos y con Enfermedades Respiratorias (FENAER), con la colaboración de AstraZeneca.

Esta iniciativa nace para identificar a los pacientes asmáticos que sobreutilizan su medicación de rescate $y$, por tanto, están descontrolados. Para ello se quiere aprovechar las visitas de estos pacientes a las farmacias cuando acuden a demandar su medicación. El objetivo es identificar a estos pacientes, realizar educación sanitaria sobre su tratamiento y su enfermedad y derivarlos al médico de familia para que pueda reevaluar el grado de control y su plan de tratamiento para el asma.

Es importante que trabajemos conjuntamente y de forma multidisciplinar con los profesionales sanitarios, para mejorar el pronóstico del paciente asmático no controlado, y además el farmacéutico comunitario goza de una posición privilegiada para identificar pacientes sobreutilizadores de los agonistas $\beta-2$ adrenérgicos de acción corta (SABA). De aquí surge la oportunidad de identificar al paciente y abordarlo cuando, a pesar de no sentir que su enfermedad no está del todo controlada, viene buscando medicación de rescate. Esto puede provocar que no se esté tratando adecuadamente la inflamación que causa la crisis asmática con posibles consecuencias sobre su salud como, por ejemplo, tener una peor calidad de vida, riesgo de agudizaciones por falta de control, etc.

Alianza contra el asma promueve la comunicación y el trabajo conjunto entre el farmacéutico comunitario y el médico para que, a través de un cuestionario sencillo y consensuado, se puedan derivar a pacientes asmáticos con sospecha de falta de control del asma para la 
revisión de su tratamiento. El proyecto consta de un curso online de atención al paciente asmático desde la farmacia comunitaria, materiales para la educación sanitaria del paciente asmático y un informe para derivar al paciente al médico de familia. Para llevar a cabo esta comunicación se implica al centro o centros de salud colindantes con las farmacias comunitarias que participan en la alianza contra el asma, presentando el proyecto en la sesión clínica del centro de salud, aunando a farmacéuticos y médicos de la zona.

Como consecuencia de esta alianza podremos aprovechar para mejorar nuestra formación en asma y debemos tener en cuenta que está demostrado que cuando el farmacéutico está formado y actúa en asma, los resultados en salud de los pacientes mejoran notoriamente (4). En el paciente asmático podremos comprobar la técnica de utilización de los diferentes dispositivos de inhalación en la dispensación, al menos una vez cada dos meses, seguir el control del paciente según cuestionarios validados como el ACT (test de control del asma), conocer la adhesión al tratamiento con cuestionarios de fácil aplicabilidad en la farmacia comunitaria y educar al paciente en su enfermedad inflamatoria crónica, en el reconocimiento de las señales de descontrol y qué hacer ante ellas y, por último, podemos resaltar que si necesita su medicación de rescate con frecuencia su enfermedad está descompensada y necesita una revisión de su enfermedad antes de que se agrave la sintomatología.
Gracias a la Alianza contra el asma podremos lograr que pacientes como Paco retomen sus actividades diarias y puedan tener controlada su enfermedad de forma satisfactoria, por lo que os animo a que os unáis a ella para trabajar conjuntamente por el paciente asmático. Si te animas dispones de más información en la web https://alianzacontraelasma.sefac.org

\section{Referencias bibliográficas}

1. Price D, Fletcher M, van der Molen T. Asthma control and management in 8,000 European patients: the REcognise Asthma and LInk to Symptoms and Experience (REALISE) survey. Npj Prim Care Respir Med [Internet]. 2014 Nov [cited 2019 Feb 1];24(1). Disponible en http://www.nature.com/articles/ npjpcrm20149

2. Olaguibel J, Quirce S, Juliá B, Fernández C, Fortuna A, Molina $\mathrm{J}$, et al. Measurement of asthma control according to global initiative for asthma guidelines: a comparison with the asthma control questionnaire. Respir Res. 2012;13(1):50. doi:10.1186/1465-9921-13-50

3. GEMA 4.3. Guía Española para el manejo del asma. Madrid; Luzán 5. 2018. Disponible en http://www.gemasma.com

4. García-Cárdenas V, Sabater-Hernández D, Kenny P, Martínez-Martínez F, Faus MJ, Benrimoj SI. Effect of a pharmacist intervention on asthma control. A cluster randomised trial. Respir Med. 2013 Sep;107(9):1346-55. doi:10.1016/j. rmed.2013.05.014 